\title{
Biosynthesis of Streptomycin
}

\section{Part I. Properties of Streptomycin-producing Supernatant Obtained from Mycelium Suspension of Streptomyces griseus}

\author{
By Ryosaku Nomi, Osamu Nimi and Toshinori MiYazaki \\ Department of Fermentation Technology, Faculty of Engineering, \\ Hiroshima University
}

Received September 27, 1965

\begin{abstract}
A precursor system for formation of streptomycin was investigated with a cell-free supernatant obtained from suspension of young mycelium of Streptomyces griseus in a nongrowth medium containing only glucose and sodium chloride. When the supernatant was kept at a slightly alkaline condition for a day, a remarkable development of antibiotic potency was observed, while the supernatant itself had a very weak potency. It was made clear by column chromatography with Sephadex G-25, CM-cellulose and DEAE-cellulose that materials required for incearse of antibiotic potency in the supernatant consisted of a cationic component with low molecular weight and an anionic one with high molecular weight. Although each of the components showed little change in antibiotic potency, the mixture of them gave rise to a remarkable increase in antibiotic potency at a slightly alkaline condition. Thus, these two components were considered to construct the precursor system appearing in the supernatant and to be able to react in a cell-free state creating the antibiotic potency.

The optimum $\mathrm{pH}$ for the reaction occuring in the supernatant was about 9 . This reaction was inhibited by phosphate or ethylenediaminetetraacetate, but not by arsenate. The precursor system was stable at and below $50^{\circ} \mathrm{C}$.
\end{abstract}

\section{INTRODUCTION}

Many investigation on the biosynthesis of streptomycin have been published dealing with the possible precursor, the origin of the radicals or residues in streptomycin molecule, and the correlation of streptomycin formation with various physiological properties of Streptomyces griseus. These were well reviewed by Hockenhull ${ }^{1 /}$ and Majumdar et al. ${ }^{2 /}$ Recently, Heding ${ }^{3)}$ and Horner ${ }^{4)}$ demonstrated labeled myoinositol to be incorporated exclusively into streptidine residue of streptomycin.

1) D. J. D. Hockenhull, "Progress in Industrial Microbiology," Vol. 2, 132 (1960); C. Rainbow and A.H. Rose, "Biochemistry of Industrial Microorganisms," Academic Press, 1963, p. 249 .

2) S.K. Majumdar and H.J. Kutzner, Appl. Microbiol., 10, 157 (1962).

3) H. Heding, Science, 143, 953 (1964).

4) W. H. Horner, J. Biol. Chem., 239, 2256 (1964).
Candy et al. $^{5)}$ found that N-methyl group in the N-methyl-L-glucosamine residue arised from the S-methyl group in methionine and $\mathrm{C}$-formyl group in the streptose residue very probably from C-3 or C-4 of glucose. Walke1 et al. ${ }^{6,7)}$ suggested the participation of amidino. transferase to transamidination from arginine to an unknown precursor of streptidine residue which was extracted from mycelium by heat They ${ }^{8)}$ showed the transamidinated precursor to be a phosphorylated derivative of strep tidine. One of the present authors ${ }^{9 /}$ demon.

\footnotetext{
5) D. J. Candy, N.L. Blumson and J. Baddiley, Biochem. $J ., 91,31$ (1964).

6) J.B. Walker and V.S. Hnilica, Biochim. Biophys. Acta 89, 473 (1964).

7) M.S. Walker and J. B. Walker, ibid., 93, 201 (1964).

8) M.S. Walker and J. B. Walker, ibid. 97, 397 (1964).

9) R. Nomi, J. Bacleriol., 86, 1220 (1963).
} 
strated that, when young mycelium of Streptomyces griseus was suspended and shaken in a non-growth medium containing a small amount of glucose and sodium chloride, the materials necessary to produce streptomycin appeared mainly in the supernatant of the suspended culture. It was supposed that the supernatant included some substance which had a weak antibiotic potency and was able to be transformed at slightly alkaline $\mathrm{pH}$ to streptomycin with a remarkable increase in antibiotic potency. The present investigation was undertaken to gain a clue to the composition of the essential substances for streptomycin formation in this supernatant.

\section{MATERIALS AND METHODS}

\section{Strain and Inoculum}

Streptomyces griseus HUT 6037 was used in all experiments. Prior to the present investigation, antibiotics produced by this strain was confirmed to be streptomycin by using paper partition chromatography, Amberlite IRC 50 resin and streptomycin-resistant Escherichia coli. This strain produced 200 to $300 \mu \mathrm{g}$ streptomycin per $\mathrm{ml}$ of glucose-meat extract-peptone medium. One loopful of aerial mycelium from a slant culture on Bennett's agar was inoculated in $10 \mathrm{ml}$ of the glucose-meat extract-peptone medium in a $50 \mathrm{ml}$ Erlenmeyer flask and cultured on a reciprocating shaker ( $105 \mathrm{rev} / \mathrm{min}$.) at $28^{\circ} \mathrm{C}$ for 2 days. One milliliter of this broth was transferred to $100 \mathrm{ml}$ of the same medium as the above in a Sakaguchi flask and cultured as indicated. The latter broth was used as an inoculum for preparation of washed mycelium. The glucose-meat extract-peptone medium consisted of $1 \%$ glucose, $0.2 \%$ yeast extract, $0.2 \%$ meat extract, $0.4 \%$ peptone, $0.5 \%$ sodium chloride, $0.025 \%$ magnesium sulfate and a small amount of defoamer (Shin-etsu Silicone KM-70). The pH of the culture medium was adjusted at 7.0.

\section{Preparation of Washed Mycelium and Active Supernatant}

One milliliter of the above-mentioned inoculum was transferred to $100 \mathrm{ml}$ of the glucose-meat extractpeptone medium in a Sakaguchi flask and cultured as indicated for 24 hours. This fermentation broth was centrifuged, harvesting the mycelium which was washed by centrifugation twice and diluted to a fixed volume with $0.5 \%$ sterile sodium chloride solution: dry weight of the diluted washed mycelium being 24 to $28 \mathrm{mg}$ per $\mathrm{ml}$. Twenty milliliter of the diluted washed mycelium was suspended in $80 \mathrm{ml}$ of $0.5 \%$ glucose solution which included $0.5 \%$ sodium chloride. The suspension was shaken on a shaker as above indicated till the $\mathrm{pH}$ value reached 6.8 to 7.0 . The $\mathrm{pH}$ of the mycelium suspension which was about 6.0 to 6.2 soon after preparation of the suspension usually decreased slighly at the early period of shaking and then gradually increased to 8.5 or cven more. Since the $\mathrm{pH}$ value more than 7.0 brings about the transformation of intermediate substance formed in mycelium suspension to streptomycin, the suspension should be centrifuged immediately when the $\mathrm{pH}$ reached 6.8 to 7.0 . The supernatant thus obtained includes all materials necessary for streptomycin formation, though its antibiotic potency is low. The supernatant usually showed the antibiotic potency equivalent to 5 to 10 units of streptomycin and increased it to 40 to 90 units by being kept at $\mathrm{pH} 8.5$ for $24 \mathrm{hr}$. This supernatant is called an active supernatant in the following sections.

\section{Expression of Antibiotic Activity}

Antibiotic potency was assayed by an agar diffusion method and expressed as microgram of streptomycin per milliliter of active supernatant or reaction mixtures, though a part of the antibiotic potency produced in those solution might be attributed to a precursor of streptomycin.

\section{RESULTS}

\section{Optimum pH for Antibiotic Development in Active Supernatant}

In the previous investigation ${ }^{9}$ performed with $S$. griseus 107, slightly alkaline $\mathrm{pH}$ value was considered optimal for the active supernatant to increase the antibiotic potency. The optimum $\mathrm{pH}$ was again examined with the present strain. The reaction of the supernatant was adjusted with $0.2 \mathrm{~N} \mathrm{HCl}$ or $0.2 \mathrm{~N}$ $\mathrm{NaOH}$ solution to $\mathrm{pH} 4.3,4.9,6.2,7.0,8.0$, 9.210 .0 and 11.1. Ten milliliter portions of the supernatant at each $\mathrm{pH}$ were placed in $50 \mathrm{ml}$ Erlenmeyer flasks with one milliliter buffer solution of the respective $\mathrm{pH}$ and a few drops of toluene, and the flasks were shaken for $24 \mathrm{hr}$. The antibiotic potency was examined before and after shaking. Sodium acetate-acetic acid buffer $(0.1 \mathrm{~m})$ was 


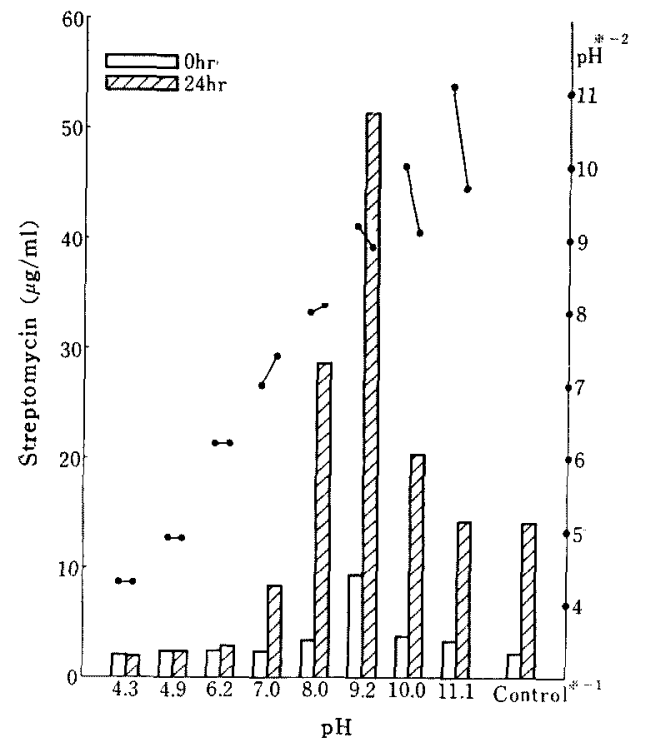

FIG. 1. Effect of $\mathrm{pH}$ on Antibiotic Development of Active Supernatant.

*-1: Without $\mathrm{pH}$ adjustment.

*-2: Scale for change of $\mathrm{pH}$ during shaking for $24 \mathrm{hr}$.

employed for $\mathrm{pH} 4.3$ and 4.9, Tris-maleate buffer $(0.05 \mathrm{M})$ for $\mathrm{pH} 6.2$ and 7.0 , Tris- $\mathrm{HCl}$ buffer $(0.05 \mathrm{M})$ for $\mathrm{pH} 8.0$, Tris- $\mathrm{HCl}$ buffer $(0.25 \mathrm{M})$ for $\mathrm{pH} 9.2$, glycine- $\mathrm{NaOH}$ buffer $(0.25 \mathrm{M})$ for $\mathrm{pH} 10.0$ and carbonate-bicarbonate buffer $(0.25 \mathrm{M})$ for $\mathrm{pH}$ 11.1. The results are given in Fig. 1 with block figures indicating the optimum $\mathrm{pH}$ to be 9.2. However, the $\mathrm{pH}$ of the supernatant was not always constant during the increasing reaction in antibiotic potency, showing the results in Fig. 1 with solid lines. When the pH of the supernatant was adjusted at 8 or 7 , it slightly increased after $24 \mathrm{hr}$ shaking. In contrary, when the $\mathrm{pH}$ was adjusted at 9.2 or higher value, it somewhat decreased after shaking. In the following experiments, $\mathrm{pH} 8.5$ was adopted as the experimental $\mathrm{pH}$ on the investigation of increase in antibiotic potency of active supernatant or other reaction mixtures.

Heat Stability of Active Supernatant

Ten milliliter portions of the active super-

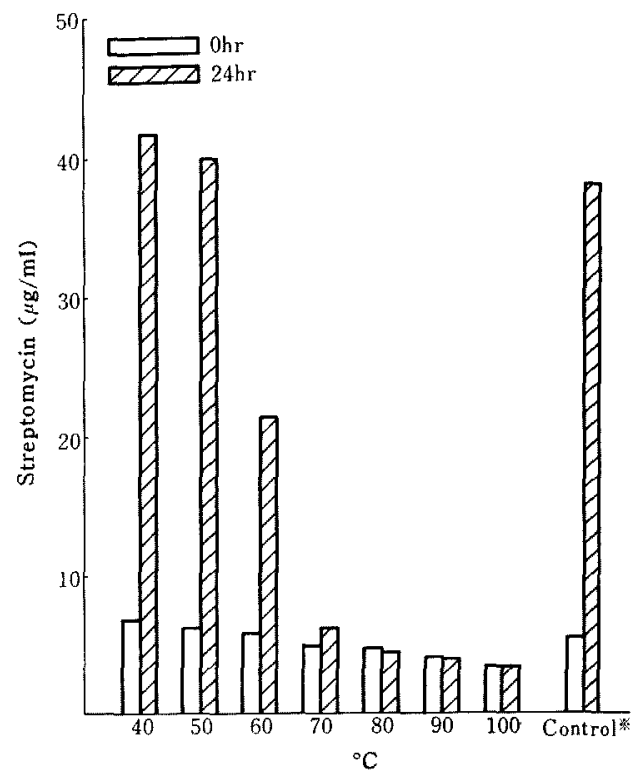

FIG. 2. Heat Stability of Active Supernatant.

*: Without heat treatment

natant in $50 \mathrm{ml}$ Erlenmeyer flasks were kept at the different temperatures indicated in Fig. 2 for 15 minutes. After cooling with tap water and addition of one milliliter of Tris$\mathrm{HCl}$ buffer $(0.05 \mathrm{M}, \mathrm{pH} 8.5)$ and a few drops of toluene, they were kept on shaker for $24 \mathrm{hr}$. The antibiotic potency was assayed before and after shaking. The results are presented in Fig. 2 which shows the active supernatant to be stable at and below $50^{\circ} \mathrm{C}$.

Inhibitor on Increase of Antibiotic Potency of Active Supernatant

A ten milliliter portion of active super. natant was mixed in a $50 \mathrm{ml}$ Erlenmeyer flask with one milliliter of potassium phosphate (dibasic) solution, one milliliter of Tris- $\mathrm{HC}$ ' buffer $(0.05 \mathrm{M}, \mathrm{pH} 8.5)$ and a few drops 0 ! toluene. The final concentrations of phos. phate in the reaction mixtures are indicatec in Fig. 3. After shaking for $24 \mathrm{hr}$, a distinc inhibitory effect of phosphate on antibioti development of the supernatant was observed Sodium arsenate (dibasic) gave no inhibitor? 


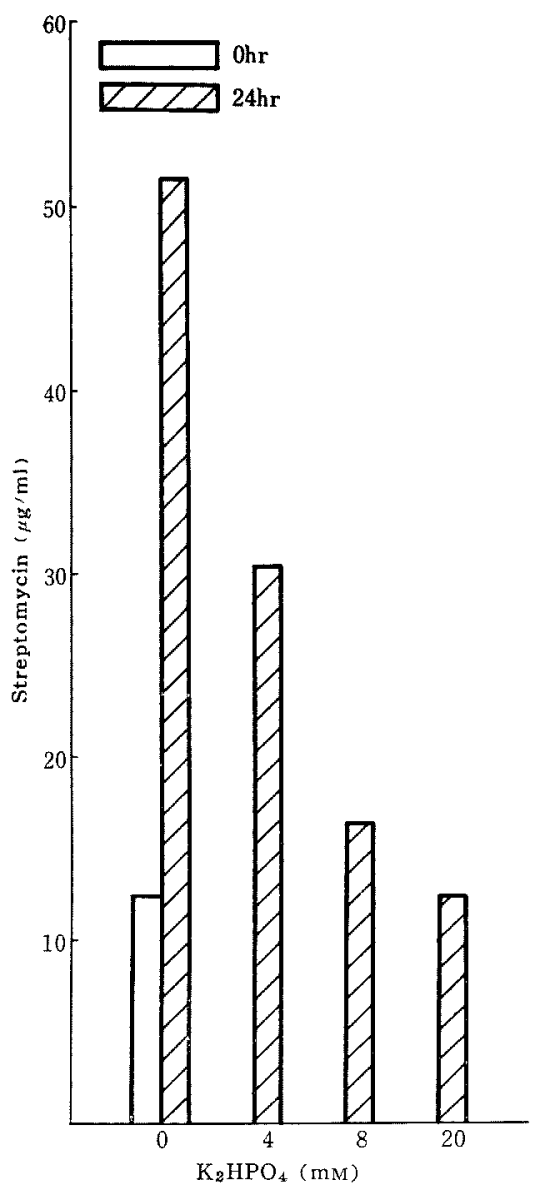

FIG. 3. Inhibitory Effect of Phosphate on Increase of Antibiotic Potency of Active Supernatant.

effect when it was used in the same concentrations as potassium phosphate. Ethylenediaminetetraacetate (disodium salt) was used in 0.027 to $1.34 \mathrm{~mm}$ final concentrations, giving a remarkable inhibitory effect shown in Fig. 4.

Gel-filtration of Active Supernatant with Sephadex G-25

To gain a clue to the ingredients of active supernatant which take part in increase of antibiotic potency, a gel-filtration of active supernatant was carried out with Sephadex G-25 (Pharmacia). Ten milliliter of the active

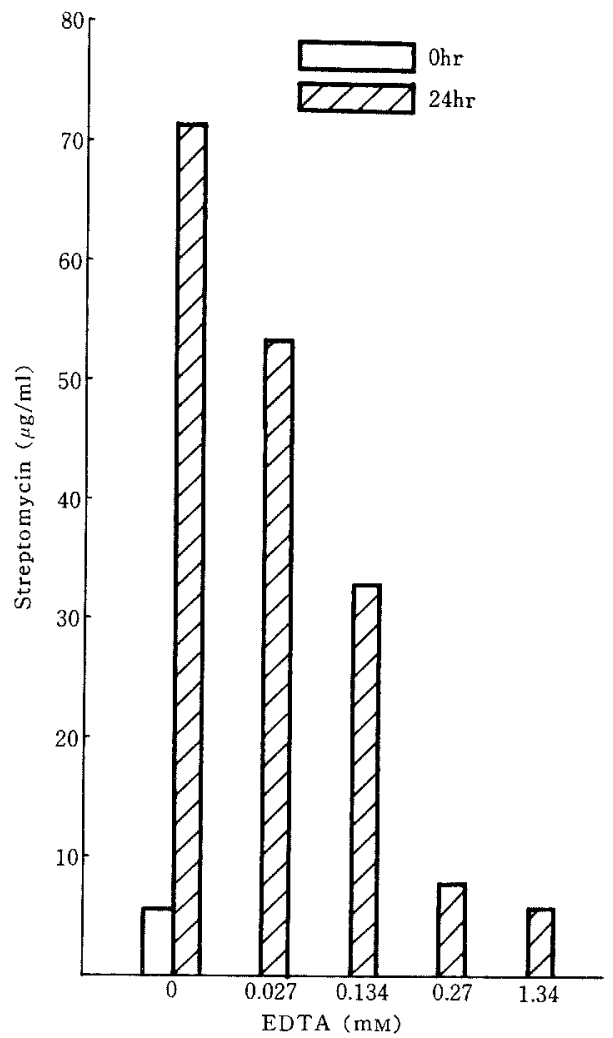

FIG. 4. Inhibitory Effect of EDTA on Increase of Antibiotic Potency of Active Supernatant.

supernatant was applied to the top of a 1.4 $\times 14 \mathrm{~cm}$ column of the Sephadex prepared in distilled water. The elution was performed by subsequent addition of $30 \mathrm{ml}$ of distilled water. The elution pattern expressed by the antibiotic potency of every $2 \mathrm{ml}$ fraction of eluate is presented in Fig. 5. For assay of antibiotic potency, $1.5 \mathrm{ml}$ of each fraction was placed in a test tube with $0.2 \mathrm{ml}$ of Tris$\mathrm{HCl}$ buffer $(0.05 \mathrm{~m}, \mathrm{pH} 8.5)$ and a drop of toluene, and the test tube was shaken for $24 \mathrm{hr}$ at $28^{\circ} \mathrm{C}$.

Since the active supernatant should retain sodium chloride included in washed mycelium suspension and very probably protein derived from mycelium, each fraction was examined 


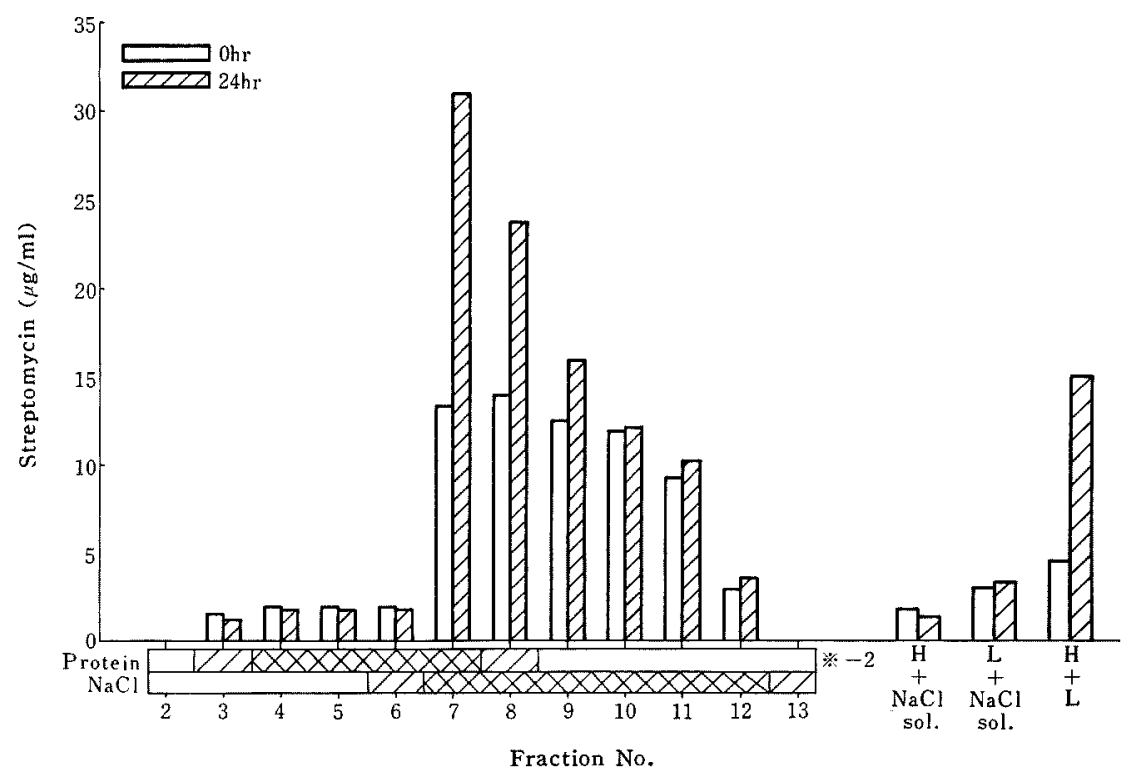

FIG. 5. Gel Filtration of Active Supernatant ${ }^{*-1}$ with Sephadex G-25.

*-1: Antibiotic potency of the active supernatant used was equivalent to $65 \mu \mathrm{g} / \mathrm{ml}$ of streptomycin after $24 \mathrm{hr}$ shaking at $\mathrm{pH} 8.5$.

*-2: $\overline{X \times X \times X \times X}$ Distinct reaction,

IIIIIIIIII Weak reaction.

Negative reaction.

on the two substances with silver nitrate and tannic acid, respectively, in order to estimate rough value of molecular weight of the materials contained in the fractions. The results are included in Fig. 5. In Fig. 5, fractions No. 3 to 6 did not increase the antibiotic potency after shaking for $24 \mathrm{hr}$ and appeared to contain high-molecular-weight substance, because in these fractions protein was detected, but sodium chloride was not. Fractions No. 9 to 12 increased the antibiotic potency slightly after shaking for $24 \mathrm{hr}$ and appeared to contain low-molecular-weight substance, because they included sodium chloride but not protein.

The fractions No. 3 to 6 and No. 9 to 12 were pooled separately, and called $\mathrm{H}$ and $\mathrm{L}$ portion, respectively. One milliliter of $\mathrm{H}$ (or L) portion was mixed in a test tube with $1 \mathrm{ml}$ of $0.5 \%$ sodium chloride solution, $0.5 \mathrm{ml}$ of Tris-HCl buffer $(0.05 \mathrm{M}, \mathrm{pH} 8.5)$ and two drops of toluene. Furthermore, $\mathrm{H}$ and $\mathrm{L}$ were mixed by one milliliter together with buffer and toluene. The antibiotic potency of these reaction mixtures were assayed before and after shaking for $24 \mathrm{hr}$ at $28^{\circ} \mathrm{C}$. The results are included in Fig. 5 . In spite of no or very little increase in antibiotic potency of the individual portions $(H$ and $L)$, the blend of their equal volume remarkably increased the antibiotic potency after $24 \mathrm{hr}$. This means that the two components included separately in $\mathrm{H}$ and $\mathrm{L}$ portions were necessary for creation of antibiotic property and they were contained simultaneously in the active supernatant.

Chromatography of Active Supernatant on CMCellulose and DEAE-Cellulose

To gain more insight into the characteristics of the components included in $\mathrm{H}$ and $\mathrm{L}$ portions, chromatography of the active supernatant on CM-cellulose (Serva) and DEAE- 


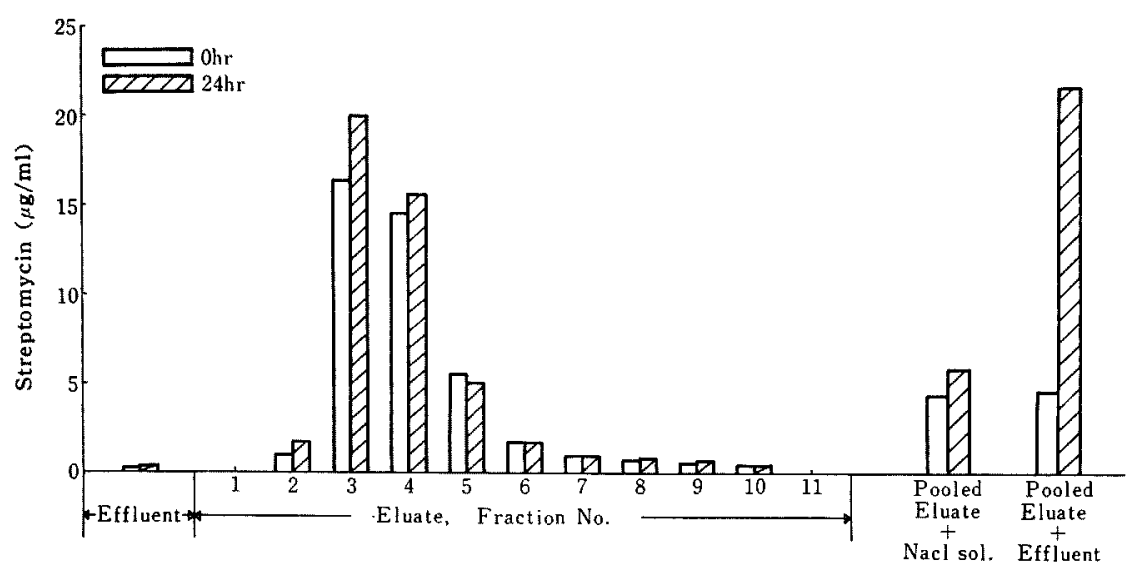

FIG. 6. Chromatography of Active Supernatant* on CM-Cellulose.

*: Antibiotic potency of the active supernatant used was equivalent to $60 \mu \mathrm{g} / \mathrm{ml}$ of streptomycin after $24 \mathrm{hr}$ shaking at $\mathrm{pH} 8.5$.

cellulose (Brown) were carried out.

A $1.4 \times 14 \mathrm{~cm}$ column of CM-cellulose which had been regenerated with $0.1 \mathrm{~N} \mathrm{HCl}$ and $0.1 \mathrm{~N} \mathrm{NaOH}$ solutions was equilibrated thoroughly with $0.05 \mathrm{M}$ Tris-maleate buffer solution $(\mathrm{pH} \mathrm{8.0)}$. Ten milliliter of active supernatant was introduced on the top of the column. Effluent was obtained by subsequent addition of distilled water onto the column. After further washing the column with distilled water, the elution of adsorbed materials was performed with the same buffer as above including $5 \%$ sodium chloride; fractions of $3 \mathrm{ml}$ were collected. Antibiotic potency of the effluent and the fractions of eluate was assayed dealing with $2 \mathrm{ml}$ of each which was mixed in a test tube with $0.2 \mathrm{ml}$ of Tris- $\mathrm{HCl}$ buffer $(0.05 \mathrm{M}, \mathrm{pH} 8.5)$ and 2 drops of toluene. The results are shown in Fig. 6. The effluent had a very weak potency and did not increase it after $24 \mathrm{hr}$ shaking. Though some of fractions in eluate had a fairly high antibiotic potency, all fractions did not remarkably increase the potency after $24 \mathrm{hr}$. Then the rest of fractions No. 3 to 6 were pooled. One milliliter of the pooled material was mixed in a test tube with $1 \mathrm{ml}$ of $0.5 \%$ sodium chloride solution, $0.2 \mathrm{ml}$ of Tris- $\mathrm{HCl}$ buffer and 2 drops of toluene. As was expected, little increase in antibiotic potency was observed in this mixture after shaking. However, at the same time, $1 \mathrm{ml}$ of the pooled eluate was blended with a same volume of effluent, buffer and toluene. As is shown in Fig. 6, this blended solution remarkably increased the antibiotic potency after $24 \mathrm{hr}$ shaking.

Chromatography of active supernatant was carried out also on a $2.8 \times 20 \mathrm{~cm}$ column of DEAE-cellulose equilibrated at $\mathrm{pH} 8.0$ with

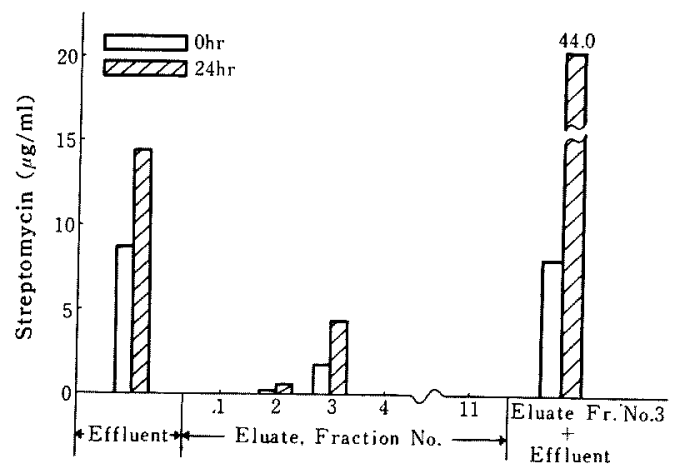

FIG. 7. Chromatography of Active Supernatant* on DEAE-Cellulose.

*: Antibiotic potency of the active supernatant used was equivalent to $96.8 \mu \mathrm{g} / \mathrm{ml}$ of streptomycin after $24 \mathrm{hr}$ shaking at $\mathrm{pH} 8.5$. 
Tris-maleate buffer solution $(0.05 \mathrm{M})$. Fifty milliliter of active supernatant was applied to the column. After recovery of the effluent and washing the column with water, elution was performed with the same buffer as above including $5 \%$ sodium chloride; fractions of $20 \mathrm{ml}$ were collected. Antibiotic potency of the effluent and eluate was assayed by the same way as used in CM-cellulose chromatography. The results are shown in Fig. 7. On the contrary to CM-cellulose chromatography, the most antibiotic potency recovered was possessed in the effluent and a little in the eluate. Then, one milliliter portions of every fraction of the eluate were placed in test tubes with $1 \mathrm{ml}$ of the effluent, $0.2 \mathrm{ml}$ of Tris-HCl buffer $(0.05 \mathrm{M} \mathrm{pH} \mathrm{8.5)}$ and 2 drops of toluene. All reaction mixtures were examined on the antibiotic potency before and after shaking for $24 \mathrm{hr}$. Only fraction No. 3 increased remarkably the antibiotic potency, while other fractions showed no or little increase in antibiotic potency.

Two kinds of effluent were prepared with CM- and DEAE-cellulose as described above.
They were examined on the complementary effect to the two portions ( $\mathrm{L}$ and $\mathrm{H}$ ) prepared with Sephadex, judging from increase in antibiotic potency. For examination of antibiotic potency of those four materials, one milliliter of each was mixed in a test tube with $1 \mathrm{ml}$ of $0.5 \%$ sodium chloride solution, $0.2 \mathrm{ml}$ of buffer and 2 drops of toluene. In the case of combination of two materials, the solution for examination consisted of one milliliter of each materials, $0.2 \mathrm{ml}$ of buffer and 2 drops of toluene. The results are presented in Fig. 8. The combination of $\mathrm{L}$ with CM-effluents as well as $\mathrm{H}$ with DEAEeffluent showed remarkable increase in antibiotic potency. Also the combination of CMeffluent with DEAE-effluent gave the similar result. It appeared likely, therefore, that the essential ingredient contained in $\mathrm{L}$ portion was also included in CM-eluate and DEAEeffluent while the essential one contained in $\mathrm{H}$ portion was done in CM-effluent and DEAE-eluate. Isolation and purification of those ingredients are now under investigation.

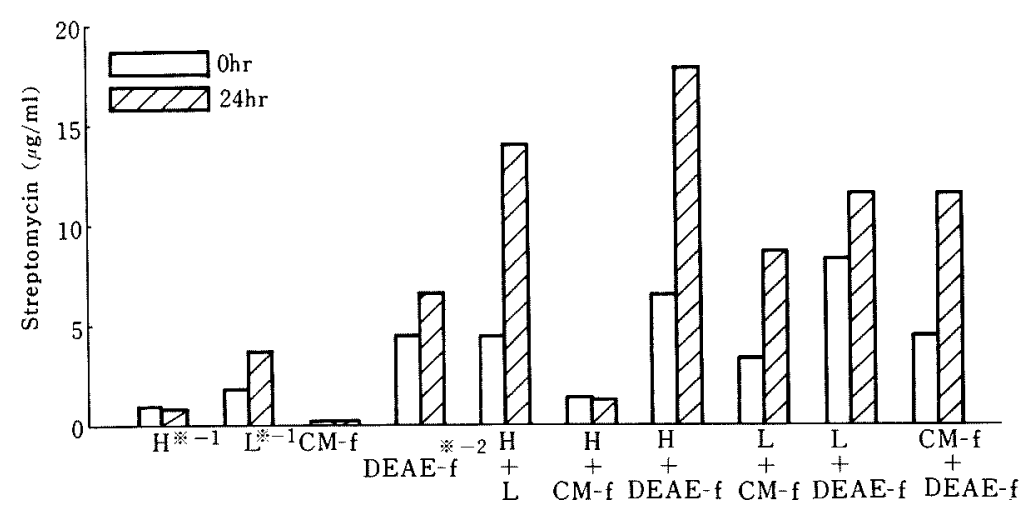

FIG. 8. Complementary Reaction among Two Effluents from Chromatography on CMand DEAE-Cellulose and Two Portions from Gel-Filtration with Sephadex G-25.

The antibiotic potency of the active supernatant used was equivalent to $48 \mu \mathrm{g} / \mathrm{ml}$ of streptomycin after $24 \mathrm{hr}$ shaking.

*-1: $H$ and $L$ portions were obtained by gel-filtration of the active supernatant with Sephadex G-25.

*-z: CM-f and DEAE-f mean the effluents obtained by chromatography of the active supernatant on CM- and DEAE-cellulose, respectively. 


\section{DISCUSSION}

It is well-known facts that the production of streptomycin by growing culture of $S$. griseus is highest when the $\mathrm{pH}$ of fermentation broth is kept at slightly alkaline condition and, on the other hand, the production is depressed by excess inorganic phosphate. But there has been no direct evidence that the reactions leading to the biosynthesis of streptomycin are most active at the slightly alkaline $\mathrm{pH}$ and are depressed by excess inorganic phosphate. In the present investigation, it was demonstrated that the transformation of the precursor contained in the active supernatant to streptomycin was optimal at slightly alkaline $\mathrm{pH}$ and was depressed by inorganic phosphate. Then, the reaction performed in the active supernatant is regarded to serve as the first and a direct evidence stated above.

The reaction discussed here is considered to play an essential role in the antibiotic activity-creating step on the biosynthetic pathway of streptomycin. This reaction was able to be performed in cell-free state between the two fractions isolated from the supernatant by column chromatography. The identical reaction should occur in the fer- mentation broth. This reaction is thought to occur at a late stage and to comprise a very few steps on the biosynthetic pathway, because streptomycin, the final product of the pathway, is easily formed merely by $\mathrm{pH}$ adjustment of the active supernatant and, besides, a successive occurance of many steps of biosynthetic reactions is considered impossible in such a cell-free state as the supernatant described above.

There is no possibility that the mannosidostreptomycinase is the main component of $\mathrm{H}$ portion, for the mannosidostreptomycinase is not affected by inorganic phosphate.

In the previous paper, ${ }^{9 \prime}$ it was shown that the supplement of glucose in washed mycelium suspension caused much more increase in antibiotic potency than without supplement. However, at the same time, fructose, inositol, D-glucosamine, lactic acid and glycerol were also effective as supplement. With respect to the origin of the precursor included in $\mathrm{L}$ portion, two ways of speculation are possible. The precursor was either produced from the glucose supplemented or released from mycelium by substitution of some metabolite of glucose for the precursor combined with cell constituent. 